References:

[1] Pregnancy outcomes in patients with ankylosing spondylitis: a nationwide register study Gustav L Jacobson, Olof Stephansson, Johan Askling and Lennart T H Jacobsson Ann Rheum Dis 2016 75: 1838-1842.

Disclosure of Interest: None declared

DOI: 10.1136/annrheumdis-2017-eular.3842

\section{AB0711 REVIEW OF MANAGEMENT OF HLA B27 POSITIVE UVEITIS PATIENT ATTENDING A TERTIARY HOSPITAL - HOW GOOD ARE WE?}

B. Kapoor ${ }^{1}$, K. Periyasamy ${ }^{1}$, M. Babbington ${ }^{1}$, A. Moorthy ${ }^{2} .{ }^{1}$ Ophthalmology; ${ }^{2}$ Rheumatology, Leicester Royal Infirmary, Leicester, United Kingdom

Background: Delay in diagnosing Spondyloarthroapthy is well documented. One of the reasons for the delay is the presentation of these group of patients to different specialties due to variety of extra articular manifestations. Acute anterior uveitis (AAU) is the most common extra-articular manifestation in HLA B27 positive spondyloarthropathies, occurring in $30-50 \%$ of cases [1]. It can occur before the onset of rheumatologic symptoms $[2,3]$. However quite often this group of patients is not routinely referred to or seen by the rheumatologist for further evaluation.

Objectives:

- To assess the ophthalmologist practice in evaluating patients with AAU for inflammatory back pain or other Rheumatological diagnoses.

- To identify the number of HLA B27 requests made for uveitis patients.

- To identify the referral rate of HLA B27 uveitis patients to Rheumatologists for evaluation.

Methods: We conducted a retrospective pilot study to assess all patients with AAU presenting over a period of one-week to our busy teaching hospital eye casualty which serves over one million population. All patients with Iritis were identified from eye causality records and medical case notes were obtained. A standard proforma was designed and piloted with few case notes initially. Modified proforma was subsequently used to collect the data which was collated and analysed using EXCEL spread sheet.

Results: A total of 62 patients $(n=62)$ with AAU presented to eye casualty over a one-week period. Case notes of 49 patients could be procured. Majority of the patients were Caucasians $(n=35)$ while the rest were Asians $(n=12)$ and blacks $(n=2)$. Sex ratio was nearly equal with 25 patients being males and the rest females. Most of our patients' age ranged between 20 to 60 years. $60 \%$ patients had a history of recurrent iritis. Out of these 9 patients had bilateral uveitis and 14 were unilateral. In 6 patients, the laterality was not documented. A history for spondyloarthropathy was elicited in only 14 patients by the ophthalmologist at the time of initial assessment. Out of these 14 patients Inflammatory back pain history was positive in 10 patients. Only 17 out of $62(27 \%)$ patients had HLA B27 checked and it was noted to be positive in 5. Amongst the 5 HLA B27 positive patients 2 patients were referred to rheumatology whereas 2 patients were already under rheumatology.

Conclusions: We observed that there is a clear lack of understanding in eliciting effective rheumatology history in patients with recurrent anterior uveitis and requesting HLA B27 appropriately. Therefore, a need for a clear pathway for managing patient presenting with recurrent uveitis and HLA B27 positivity for evaluation of Inflammatory back pain. Clear local guidelines and pathway need to be developed to provide effective care. Good communication between the Ophthalmologist and Rheumatologist is key in early diagnosis and effective management of this deforming condition.

\section{References:}

[1] Khan AK. A worldwide overview: the epidemiology of HLA-B27 and associated spondyloarthritides. In: Calin A, Taurog JD, eds. The Spondylarthritides. Oxford: Oxford University Press, 1998: 17-26.

[2] Careless DJ, Inman RD. Acute anterior uveitis: clinical and experimental aspects. Semin Arthritis Rheum. 1995 Jun. 24(6):432-41.

[3] Chang JH, McCluskey PJ, Wakefield D. Acute anterior uveitis and HLA-B27. Surv Ophthalmol. 2005 Jul-Aug. 50(4):364-8.

Disclosure of Interest: None declared

DOI: 10.1136/annrheumdis-2017-eular.4511

\section{AB0712 CLINICAL CHARACTERISTICS OF SPONDYLARTHRITIS (SPA) WITH AND WITHOUT PERIPHERAL ENTHESITIS - DATA FROM THE DESIR COHORT}

V. Nadon ${ }^{1}$, A. Molto ${ }^{2}$, A. Etcheto ${ }^{2}$, L. Bessette ${ }^{3}$, L. Michou ${ }^{3}$, P. Claudepierre ${ }^{4}$, D. Wendling ${ }^{5}$, C. Tkaczyk ${ }^{6}$, B. Haraoui $^{1}$, M. Dougados ${ }^{2} .{ }^{1}$ Institut de Rhumatologie de Montreal, Montreal, Canada; ${ }^{2}$ Hôpital Cochin, Paris, France, ${ }^{3} \mathrm{CHUL}$, Quebec, Canada; ${ }^{4}$ Hôpital Henri Mondor, Créteil; ${ }^{5} \mathrm{CHRU}$, Besançon, France; 6 Janssen, Montreal, Canada

Background: Peripheral enthesitis, mostly in the lower limbs, is a major feature of spondyloarthritis $(\mathrm{SpA})$. Its prevalence is highly variable depending on the population studied, estimated between $10 \%$ and $70 \%$. The probability to develop a peripheral enthesitis over time and the factors associated with it are mostly unknown.

Objectives: The aims of the present study were: 1) To describe the prevalence and characteristics of peripheral enthesitis in early axial SpA population, at the inclusion in the DESIR cohort; 2) to estimate the incidence of peripheral enthesitis over time; 3 ) to determine the factors associated with the presence of peripheral enthesitis.

Methods: We used data from the DESIR cohort, a prospective multi-center, longitudinal French cohort of 708 patients with inflammatory back pain suggestive of early axial SpA ( $<3$ years since axial symptoms onset). We performed a descriptive analysis to evaluate the prevalence and characteristics of the peripheral enthesitis at time of inclusion (location, number of enthesitis, and mean time between first enthesitis and axial symptoms). We also estimated the incidence of peripheral enthesitis over a follow up period of 60 months, using Kaplan-Meier curves. Finally, we determined the baseline characteristics associated with the presence of a peripheral enthesitis by multivariable analysis (logistic regression, including the variables significantly associated in the univariable analysis).

Results: At inclusion, 395 patients (55.8\%) had peripheral enthesitis in their past medical history. The locations were mainly the plantar fascia $(212 / 395,53.7 \%)$ and the Achilles tendon (152/395, 38.5\%). Seventy-seven (19.4\%) of these patients developed peripheral enthesitis before their axial symptoms, with a mean time interval of 773 days. During the 5-year follow-up period, 109/708 (15.4\%) patients developed new peripheral enthesitic symptoms, resulting in 504/708 $(71.2 \%)$ patients who had presented with at least one episode of peripheral enthesitis at 5 years. Variables associated to peripheral enthesitis according to the univariable analysis were: older age, male gender, HLA B27 positivity, MRI sacroilitis, Modified NY criteria fulfilled, presence of either anterior chest wall pain, peripheral arthritis, dactylitis or psoriasis, high BASDAI, BASFI or mean score ASAS-NSAID. Only the history of anterior chest wall pain and of peripheral arthritis were significantly and independently associated with the presence of peripheral enthesitis in the multivariable analysis (Odds Ratio (OR) $=1.6[95 \%$ Confidence interval $(1.6[1.1-2.3]$, and $\mathrm{OR}=2.1$ [1.4-3.0], respectively)

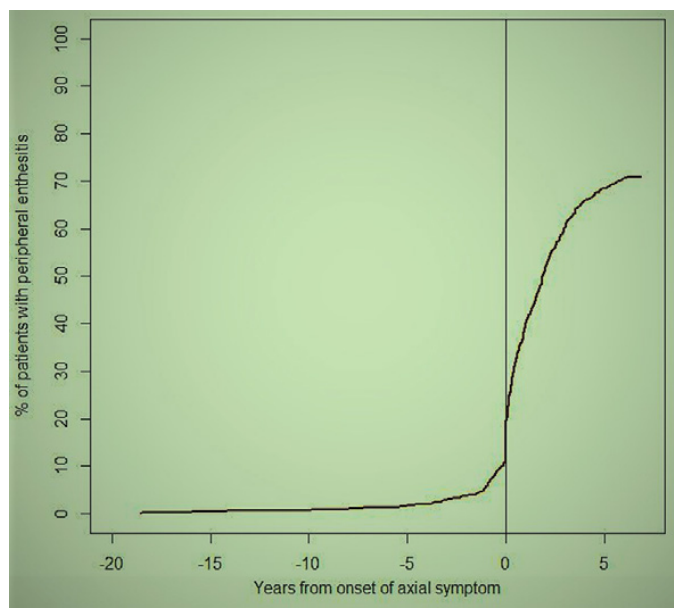

Conclusions: This prospective study highlights the high prevalence of peripheral enthesitis in early axial SpA and stresses the importance of researching any signs and symptoms of enthesitis, especially in those patients with anterior chest wall pain and peripheral arthritis.

References:

[1] Sampaio-Barros, PERCIVAL DEGRAVA, et al. Primary ankylosing spondylitis: patterns of disease in a Brazilian population of 147 patients. The Journal of rheumatology 28.3 (2001): 560-565.

Disclosure of Interest: V. Nadon: None declared, A. Molto: None declared, A. Etcheto: None declared, L. Bessette: None declared, L. Michou: None declared, P. Claudepierre: None declared, D. Wendling: None declared, C. Tkaczyk Grant/research support from: This projet was partly supported by an unrestricted grant from Janssen Canada, B. Haraoui: None declared, M. Dougados: None declared

DOI: 10.1136/annrheumdis-2017-eular.5087

\section{AB0713 UVEITIS SECONDARY TO SPONDYLARTHRITIS IN AN OCULAR INFLAMMATION INTERDISCIPLINARY UNIT}

D. Peiteado ${ }^{1}$, A. Pieren ${ }^{1}$, A. Schlinker ${ }^{2}$, V. Hidalgo ${ }^{2}$, C. Millán ${ }^{1}$, E. De Miguel ${ }^{1}$, A. Balsa ${ }^{1} \cdot{ }^{1}$ Rheumatology; ${ }^{2}$ Ophthalmology, Hospital Universitario la Paz, Madrid, Spain

Objectives: To describe the characteristics of ocular involvement in spondyloarthritis in an ocular inflammation interdisciplinary unit.

Methods: This descriptive study include the patients with uveitis secondary to spondyloarthritis or inflammatory bowel disease (IBD) treated by the rheumatologist from January 2012 to December 2016 in an ocular inflammation multidisciplinary unit. Demographic characteristics, aetiology, ocular involvement pattern, and systemic therapy data were collected and analysed.

Results: From 276 patients evaluated by the rheumatologist, 111 (40.2\%) were uveitis secondary to systemic inflammatory diseases. Within this group, the uveitis 